\title{
Melanoma conjuntival en ojo izquierdo
}

\section{Conjunctival melanoma in left eye}

\author{
René Hernán Parada-Vásquez ${ }^{1 *}$, Juan Pablo Medina-López² y Carlos Mario Velasco-Calvo ${ }^{3}$ \\ ${ }^{1}$ Becario de segmento anterior; ${ }^{2}$ Residente de tercer año de Oftalmología; ${ }^{3}$ Residente de segundo año de Oftalmología. Instituto de la visión, \\ Hospital La Carlota, Montemorelos, Nuevo León, México
}

Paciente varón, de 78 años de edad, que acude a la consulta por disminución de la visión del ojo izquierdo de manera progresiva en el último año. No refiere antecedentes clínicos. Su capacidad visual es de 20/40 en el ojo derecho, y cuenta dedos a $2 \mathrm{~m}$ con el izquierdo. Al examen físico en ojo izquierdo: se evalúan ducciones y versiones, encontrando una limitación a la supraducción en el ojo izquierdo. Se observa una lesión nodular, pigmentada, de $2 \mathrm{~mm}$ de elevación, con un tamaño de $13 \times 8 \mathrm{~mm}$ de diámetro, de bordes regulares, vascularizada, con vasos nutricios dilatados en la conjuntiva bulbar (fig. 1); llega a extenderse a la zona limbar en su porción temporal, involucrando un

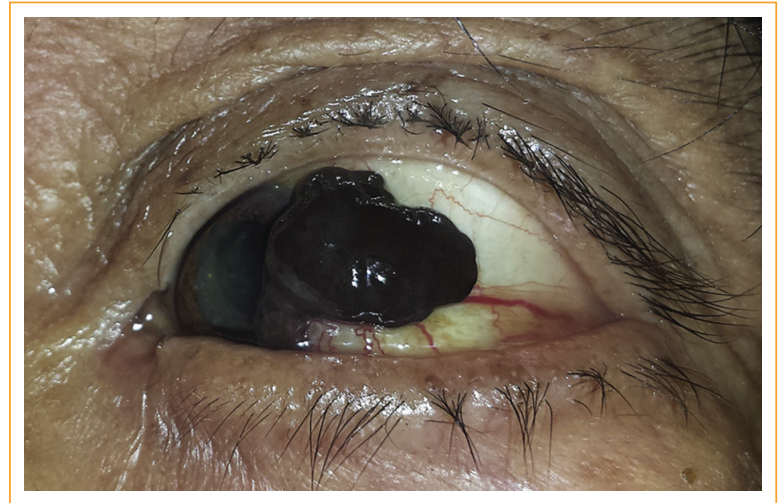

Figura 1. Vista de frente. Se aprecia lesión nodular pigmentada, con bordes regulares y vasos nutricios dilatados en la conjuntiva bulbar. área corneal de $6 \times 2 \mathrm{~mm}$ de diámetro (fig. 2). El resto del segmento anterior con características normales. Fondo de ojo con degeneración miópica.

\section{Responsabilidades éticas}

Protección de personas y animales. Los autores declaran que para esta investigación no se han realizado experimentos en seres humanos ni en animales.

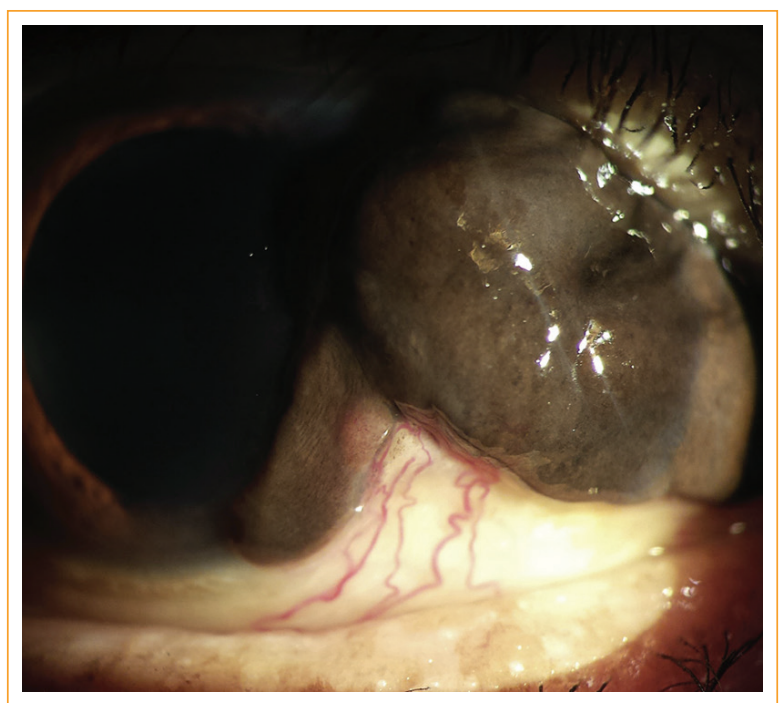

Figura 2. Lesión pigmentada, que se extiende a la zona limbar en su porción temporal.

\section{Correspondencia:}

*René Hernán Parada-Vásquez

E-mail: rene_hernan@ @otmail.com CC BY-NC-ND (http://creativecommons.org/licenses/by-nc-nd/4.0/)
Disponible en internet: 29-12-2016 Rev Mex Oftalmol. 2018;xx(x):1-2 www.rmo.com.mx 
Confidencialidad de los datos. Los autores declaran que ha seguido los protocolos de su centro de trabajo sobre la publicación de datos de pacientes.

Derecho a la privacidad y consentimiento informado. Los autores han obtenido el consentimiento informado de los pacientes y/o sujetos referidos en el artículo. Este documento obra en poder del autor de correspondencia.

\section{Financiamiento}

Los autores no recibieron patrocinio para llevar a cabo este artículo.

\section{Conflicto de intereses}

Los autores declaran no tener ningún conflicto de intereses. 